\title{
EFEITOS DO USO DE AGENTES CLAREADORES DE AUTO-APLICAÇÃO SOBRE A SUPERFÍCIE DE UMA RESINA COMPOSTA NANOPARTICULADA
}

\author{
Francine Lima $^{1}$; Alex Correia Vieira ${ }^{2}$ \\ 1. Bolsista PIBIC/FAPESB, Graduanda em Odontologia, Universidade Estadual de Feira de Santana, e-mail: \\ francendk@hotmail.com \\ 2. Orientador, Departamento de Saúde, Universidade Estadual de Feira de Santana, e-mail: vieira.leko@gmail.com
}

PALAVRAS-CHAVE: Clareamento Dental; Peróxido de Hidrogênio; Materiais Dentários

\section{INTRODUÇÃO}

Uma das maiores preocupações atuais na Odontologia está relacionada à tentativa de encontrar um material restaurador que se assemelhe à estrutura dental perdida, e que este seja de rápida e fácil aplicação, biocompatível, custo acessível, apresente uma boa adesão aos tecidos dentais e longevidade clínica satisfatória. Neste contexto, a resina composta se destaca como material ideal (CAMACHO et al., 2008).

No entanto, algumas questões são preocupantes com relação a este material restaurador, dentre estas, a impossibilidade de formar uma superfície perfeitamente lisa. Esta irregularidade superficial pode provocar problemas clínicos como: descoloração e manchas superficiais, acúmulo de placa bacteriana e consequentes danos à saúde periodontal, podendo ainda, levar o aparecimento de cáries secundárias (CAMACHO et al.,2008).

Alguns tratamentos odontológicos, como o clareamento dental, podem promover alterações na rugosidade superficial destes materiais restauradores. Neste contexto, os efeitos dos agentes clareadores aplicados sobre esses materiais restauradores têm sido relatados em vários estudos (KABBACH et al., 2006; CAMACHO et al., 2008; RAMOS et al., 2014). Atualmente, foram introduzidos no mercado sistemas de clareamento caseiro que dispensam o uso de moldeira individual, determinados como produtos de auto-aplicação, compostos, geralmente, por peróxido de hidrogênio em baixas concentrações (CONCEIÇÃO et al., 2007).

Diante disto, faz-se necessário a realização de estudos para avaliar os possíveis efeitos deletérios destes produtos, devido ao seu largo uso e amplo acesso no mercado atual. Este trabalho teve como objetivo avaliar a alteração da rugosidade superficial de uma resina composta anoparticulada (Filtek Z350 XT ${ }^{\circledR}, 3 \mathrm{M}$-ESPE) após o uso de produtos clareadores de auto-aplicação contento baixa concentração de peróxido de hidrogênio.

\section{MATERIAL E MÉTODOS}

O presente trabalho trata-se de um estudo experimental in vitro, no qual foram testados os seguintes materiais: a resina composta nanoparticulada Filtek Z350 XT ${ }^{\circledR}$ (3M-ESPE), a fita clareadora Crest 3D White Professional Effects Whitestrips ${ }^{\circledR}$ (Procter \& Gamble, USA) e o pincel Pretty Smile ${ }^{\circledR}$ (DMC, São Paulo Brasil). Assim, foram confeccionados 30 corpos de prova com a resina composta selecionada, sendo utilizada uma matriz metálica retangular com $10,0 \mathrm{~cm}$ de comprimento, $3,0 \mathrm{~cm}$ de largura e 2,0 $\mathrm{mm}$ de espessura, contendo 5 perfurações medindo 5,0 $\mathrm{mm}$ de diâmetro interno por 2,0 $\mathrm{mm}$ de espessura, que determinaram as medidas 
destas amostras. Os pesquisadores foram devidamente calibrados, por meio da reprodução de todos os passos da metodologia em um estudo piloto, realizado previamente à pesquisa propriamente dita.

Durante a confecção dos corpos de prova, as perfurações desta matriz foram devidamente isoladas com vaselina sólida, para evitar a adesão do material, e o compósito foi inserido em seus orifícios com auxílio de uma espátula de titanium na forma de incremento único, sendo em seguida fotopolimerizado seguindo o tempo recomendado pelo fabricante, contra uma tira de poliéster pressionada por uma placa de vidro, com o auxílio de um fotopolimerizador Led Curing Light, com intensidadede luz de 1,400 $\mathrm{mW} / \mathrm{cm}^{2}$, aferida através de um radiômetro (Demetron/Kerr, Danbury, CT, EUA). Estas amostras foram então armazenadas em um pote plástico coletor contendo saliva artificial, para evitar a desidratação do material.

Então, os corpos de prova foram divididos em 3 grupos, cada um contendo 10 amostras, os quais receberam diferentes tratamentos, conforme a tabela abaixo.

Tabela 1- Divisão dos grupos

\begin{tabular}{|c|c|c|}
\hline GRUPO & MATERIAL RESTAURADOR & PROCEDIMENTO \\
\hline $\begin{array}{l}\text { G1 } \\
\text { (Controle) }\end{array}$ & Filtek Z350 XT ${ }^{\circledR}$ & $\begin{array}{l}\text { Nenhum tratamento } \\
\text { clareador }\end{array}$ \\
\hline G2 & Filtek Z350 XT ${ }^{\circledR}$ & $\begin{array}{l}\text { Clareamento com } \\
\text { Peróxido de Hidrogênio a } \\
10 \% \text {. }\end{array}$ \\
\hline G3 & Filtek Z350 XT ${ }^{\circledR}$ & $\begin{array}{l}\text { Clareamento com } \\
\text { Peróxido de Hidrogênio a } \\
7,7 \% \text {. }\end{array}$ \\
\hline
\end{tabular}

Posteriormente, os grupos foram submetidos aos procedimentos clareadores utilizando os seguintes produtos: Crest 3D White Professional Effects Whitestrips ${ }^{\circledR}$ (Procter \& Gamble, USA), contendo peróxido de hidrogênio a $10 \%$ e o pincel Pretty Smile (DMC, São Paulo Brasil), com concentração de 7,7 \%, seguindo as recomendações do fabricante.

Para isto, os corpos de prova foram fixados em uma placa de vidro com cera rosa $\mathrm{n}^{\circ} 7$. O produto foi aplicado sobre a superfície destas amostras e mantido durante o tempo de 30 minutos, duas vezes ao dia. Após este período, as mesmas foram lavadas, secas e novamente armazenadas em saliva artificial. Este procedimento foi reproduzido durante 10 dias.

Finalizado o clareamento após este período, cada corpo de prova foi fixado com fita dupla face em uma placa de vidro e submetido à leitura no rugosímetro Surftest SJ-301 (Mitutoyo, Tokyo, Japão), para determinar a sua rugosidade superficial média. A leitura considerada foi a média aritmética $(\mathrm{Ra})$ entre os picos e vales percorridos pela ponta ativa do aparelho, no qual o percurso de medição foi de $4,0 \mathrm{~mm}$. Foram realizadas três leituras em cada amostra: uma no sentido horizontal, outra perpendicular a primeira e uma no sentido oblíquo.

O programa utilizado para a compilação dos dados foi o Statistical Package for Social Science - SSPS versão 20.0. As informações foram sistematizadas em tabelas e gráficos com 
o auxílio do Programa Excel da MICROSOFT CORPORATION (2010). As médias dos valores obtidos foram submetidas à análise estatística por meio da análise de variância (ANOVA) e teste de Tukey, nível de significância de 5\% para comparações múltiplas.

\section{RESULTADOS E DISCUSSÃO}

Os valores da rugosidade superficial média (Ra) dos grupos testados estão apresentados na tabela 2. De acordo com estes achados, foram observadas diferenças estatísticas significantes entre o grupo controle $(\mathrm{G} 1)$ e os demais grupos, submetidos à ação do peróxido de hidrogênio em baixas concentrações $(\mathrm{p}<0,05)$. Portanto, a rugosidade superficial da resina composta foi influenciada negativamente pelo procedimento clareador realizado.

Tabela 2 - Rugosidade superficial média ( $\mathrm{Ra}$ ) dos grupos experimentais, em $\mu \mathrm{m}$, apresentadas como média e desvio padrão (dp)

GRUPO MÉDIA (Ra) DESVIO PADRÃO (dp)

\begin{tabular}{ccc}
\hline G1 & $0,36 \mathrm{a}$ & 0,09 \\
$\mathbf{G 2}$ & $0,61 \mathrm{~b}$ & 0,17 \\
$\mathbf{G 3}$ & $0,54 \mathrm{~b}$ & 0,09 \\
\hline
\end{tabular}

Médias seguidas de letras diferentes indicam diferença estatisticamente significante

Quando analisados os grupos submetidos ao clareamento com o peróxido de hidrogênio em diferentes concentrações entre si (G2 e G3), também não foi encontrada diferença significativa ( $p>0,05$ ), não sendo a diferença de concentração e forma de aplicação dos produtos, fatores determinantes na alteração da rugosidade superficial média da resina testada.

Assim, neste estudo foram encontradas diferenças significativas entre os valores da rugosidade superficial média em relação aos grupos controle e tratados com peróxido de hidrogênio à 7,7 e 10\%. Este resultado está de acordo com o estudo de Jaeger et al. (2005), em que foi encontrado um aumento da rugosidade superficial da resina microhíbrida Z250 (3M-ESPE ${ }^{\circledR}$, USA) exposta ao peróxido de carbamida a $10 \%$ após um período de 30 dias. Em contrapartida, Pitacas et al. (2015), observaram um aumento da rugosidade superficial na resina nanohíbrida (Tetric EvoCeram®) e nananoparticulada (Filtek Supreme Z350 XT®), após o uso de agentes clareadores a 10 e 22\%. Wongpraparatana e colaboradores (2017) também encontraram que o tratamento com $10 \%$ de peróxido de carbamida ou $40 \%$ de peróxido de hidrogênio aumentou a rugosidade superficial de uma resina composta nanoparticulada. Já Bahannan (2015), ao contrário, relatou que não foram encontradas diferenças significativas na rugosidade de resinas compostas após o uso do peróxido de carbamida a $10 \%$. 
Ainda que a eficácia dos agentes clareadores seja observada, seu efeito sobre as resinas compostas é controverso. Alguns autores relatam que os resultados divergentes entre os vários estudos podem se dar devido aos diferentes agentes, produtos de clareamento e materiais restauradores, além de diferenças na frequência da aplicação dos agentes de clareamento (PITACAS et al., 2015).

Neste trabalho buscou-se simular o comportamento da resina no interior da cavidade bucal utilizando-se saliva artificial como meio de armazenamento. Porém, esbarrou-se em limitantes como a ausência de importantes funções fisiológicas presentes na saliva natural, bem como a escassez de dados na literatura sobre a utilização dos produtos de autoaplicação, denotando a importância do presente estudo.

\section{CONCLUSÃO}

A rugosidade superficial da resina composta nanoparticulada apresentou aumento em seus valores, quando exposta aos produtos clareadores com baixas concentrações de peróxido de hidrogênio. Porém, as diferenças de concentrações entre estes não foram determinantes em promover alterações significativas na sua rugosidade.

\section{REFERÊNCIAS}

BAHANNAN S.A. Effects of different bleaching agent concentrations on esthetic restorative materials. The Saudi Journal for Dental Research (2015) 6, 124-128

CAMACHO G.B.; NEDEL F; MARTINS G.B et al. Avaliação da rugosidade superficial de resinas compostas expostas a diferentes agentes. Rev Odontol UNESP. 2008; 37(3):211-6.

CONCEIÇÃO, E. N. et al. Dentística: saúde e estética. 2. ed. Porto Alegre: Artmed, 2007. 596 p. (Série Odontologia)

JAEGER F, POZZOBON R.T., SOUZA N.C.. Análise da rugosidade superficial de uma resina composta exposta a diferentes meios de imersão e tempos. Rev InstCiêncSaúde 2005 abr-jun;23(2):115-9

KABBACH et al. Avaliação da rugosidade superficial de resina composta após a ação de agentes clareadores imediatos. Rev. Uniara., n. 17-18, p. 239-47. 2005/2006

PITACAS et al. Effect of external tooth bleaching on the surfasse of resin composites - An in vitro study.Rev Port Estomatol Med Dent Cir Maxilofac. 2015

RAMOS AB, MONNERAT AF, PEREZ CR. Avaliação da eficácia das fitas para clareamento dental. Rev. Bras. Odontol. 2014; 71(2):198-202.

WONGPRAPARATANA I et al. Effect of Vital Tooth Bleaching on Surface Roughness and Streptococcal Biofilm Formation on Direct Tooth-Colored Restorative Materials. Operative Dentistry, 0000, 00-0, 000-000. 2017 